\title{
EDUCATION
}

\section{Blended Learning: Transformation of Phlebotomy Education at Mayo Clinic}

\author{
MARY KAYE T. PETERSON, RANDY C. GRUHLKE, RODERICK C. SIMS, VIRGINIA M. \\ WRIGHT-PETERSON, BRAD S. KARON, TROY A. TYNSKY, DARCI L. LAMMERS, CLAIRE E. \\ BENDER, MICHAEL H. SILBER, BETHANY A. KROM, MARY S. LESSARD
}

\section{ABSTRACT}

Blended learning, a combination of online and face-toface classroom experiences, is of particular interest in health sciences education. Mayo School of Health Sciences, one of the five schools within the Mayo Clinic College of Medicine, assessed the use of blended learning across three allied health education programs: clinical neurophysiology, histology, and phlebotomy. The process involved analysis of the individual programs and the establishment of a philosophy to underpin the use of blended learning within the school. To evaluate the results of the redesigned blended phlebotomy program that was implemented in September 2012, we collected data on resource use, program accessibility, student performance, and student satisfaction. The results showed that the blended learning environment enhanced the overall course framework, by providing greater accessibility (geographically and temporally), and improved efficiency in the use of faculty, classroom and laboratory space; while maintaining strong student performance. Although student satisfaction decreased initially, program adjustments resulted in subsequent student cohorts reporting high satisfaction. We showed the utility of blended learning being adopted in health sciences programs traditionally delivered face-to-face and the value of technology used effectively in teaching and learning.

ABBREVIATIONS: MSHS - Mayo School of Health Sciences, NAACLS - National Accrediting Agency for Clinical Laboratory Sciences

INDEX TERMS: Blended learning; online education; phlebotomy education

Clin Lab Sci 2016;29(4):219-226

Mary Kaye T. Peterson, MS, Mayo School of Health Sciences, Mayo Clinic College of Medicine, Rochester,
$M N$

Randy C. Grublke, MS, Mayo School of Health Sciences, Mayo Clinic College of Medicine, Rochester $M N$

Roderick C. Sims, PhD, Knowledgecraft Educational Design Consultant, Woodburn NSW, Australia

Virginia M. Wright-Peterson, MA, Mayo School of Health Sciences, Mayo Clinic College of Medicine, Rochester $M N$

Brad S. Karon, MD, PhD, Mayo School of Health Sciences, Mayo Clinic College of Medicine, Rochester $M N$

Troy A. Tynsky, MEd, Mayo School of Health Sciences, Mayo Clinic College of Medicine, Rochester MN

Darci L. Lammers, PhD, Mayo School of Health Sciences, Mayo Clinic College of Medicine, Rochester $M N$

Claire E. Bender, MD, Mayo School of Health Sciences, Mayo Clinic College of Medicine, Rochester $M N$

Michael H. Silber, MD, Mayo School of Health Sciences, Mayo Clinic College of Medicine, Rochester $M N$

Bethany A. Krom, Mayo School of Health Sciences, Mayo Clinic College of Medicine, Rochester MN

Mary S. Lessard, Mayo School of Health Sciences, Mayo Clinic College of Medicine, Rochester MN

Address for Correspondence: Brad S. Karon, MD, 
PhD, Mayo School of Health Sciences, Mayo Clinic College of Medicine, 200 First St SW, Rochester, $M N$ 55905,507-538-4921, karon.bradley@mayo.edu

\section{INTRODUCTION}

Mayo School of Health Sciences (MSHS), one of five schools in the Mayo Clinic College of Medicine, embarked on a comprehensive project to create a blended learning environment designed to transform 3 programs offered by the school: clinical neurophysiology, histology, and phlebotomy. The 3 key aims of the project were to 1) increase accessibility across both geography and time; 2) improve efficiency in the use of faculty time, classroom resources, and shared curricula; and 3) maintain or improve student learning and satisfaction.

\section{The Phlebotomy Technician Program}

The MSHS phlebotomy technician program prepares students for careers as phlebotomists in outpatient or inpatient settings by giving them didactic, laboratory, and clinical experiences. The curriculum includes medical terminology, anatomy and physiology, customer service skills, safety procedures, venous (venipuncture) and capillary (fingerstick and heelstick) blood collection techniques, arterial and venous blood collection techniques for blood gas analysis, a broad perspective of laboratory processing, and computer skills. The program is approved by the National Accrediting Agency for Clinical Laboratory Sciences (NAACLS), so graduates are eligible to take the professional certification examinations.

The program includes approximately 160 clinical training hours in addition to didactic and laboratory teaching. Before the shift to blended learning, the phlebotomy technician program was offered as a fulltime, on-campus 10-week program. The face-to-face program was based on 2 sequential courses, Introductory Phlebotomy and Advanced Phlebotomy. For the blended learning project, each course was subdivided into a series of modules.

\section{Blended Learning}

Broadly, the term blended learning refers to a combination of on-campus, face-to-face activities and off-campus, online learning resources, activities, and assessments. Pape defined blended learning as "using online tools to communicate, collaborate, and publish ... to develop the 21 st-century skills students need ... teachers can use online tools and resources as part of their daily classroom instruction." ${ }^{1}$ An important element of blended learning is that the technology will not in itself create the desired transformations. Rather, those transformations occur through the implementation of teaching and learning activities that align with appropriate learning theories and instructional design practices (i.e., pedagogy).

The foundation for success in blended learning is to base implementation decisions on a combination of strategic organizational and instructional needs and not on a technologic interest. Consequently, the selection of technologies is based on informed decisions that align with required learning outcomes. Underpinning the blended learning project was a broad vision for education across the school. As the driving vision for the school, the benefits of blended learning are 1) strategically aligned, 2) evidence-based, 3) pedagogically driven, and 4) technologically enabled.

The strategic goals of MSHS determine key focus points for blended learning, such as the extension of access and delivery options beyond the current on-campus model and the opportunity to share curricula across programs and schools and within the employee base when relevant. The evidence supporting the decisions is synthesized from existing program evaluation data, research in online and blended learning, and research in learning theories and curriculum design.

The pedagogy of blended learning embodies a constructivist (aligned with constructivism theory positing that learning is an active process in which new ideas are constructed based upon current or past knowledge), contextual (learning in the context or situation where knowledge will be applied), and authentic (learning using realistic or accurate problems faced in real world situations) learning model that advocates a learner-centered and collaborative approach to teaching and learning. Blended learning, the combination of face-to-face and distance interactions, requires a strong pedagogical framework and acceptance of the aligned theories. Because blended learning parallels the growth of the Internet and the availability of valid knowledge sources, the learning experience shifts from a teacher-centered to a learner-centered environment. Use of computer-based tools also aligns with a constructivist approach to learning, which is predicated on the use of 
social (person-to-person) and virtual (person-tomachine) interactions and the means by which these interactions assist in the construction of meaning. Blended learning options, therefore, are a function of the pedagogy of the program and the course.

The technology of blended learning revolves around a learning management system (currently Blackboard [Blackboard, Inc.]), the Internet, and a range of selfpaced, collaborative or networked tools. Blended learning uses computer-based technologies to enable the strategic and pedagogical attributes to be implemented, including simulations, telemedicine (video links), virtual classrooms, self-assessment, and synchronous communications.

For best practice, Brandt et al suggested that "a blended or hybrid learning model that strategically uses webbased and face-to-face teaching/learning methods is an innovative and strategic way that promotes learnercentered higher education and facilitates a higher learning experience." ${ }^{2}$ The experiences documented by Brandt et $\mathrm{al}^{2}$ in the early stages of adopting blended learning were critical for our project to ensure that we developed a contemporary and integrated outcomesbased curriculum.

The purpose of our study was to assess how blended learning affected the phlebotomy technician program, which had been based on traditional face-to-face didactic, laboratory, and clinical practice sessions.

\section{MATERIALS AND METHODS}

The data were primarily collected from student evaluations and performance scores from two cohorts (called Preblended) who completed the program in May 2012 or August 2012, before blended learning was implemented in September 2012; and from four cohorts (called Blended 1-4) who completed the program in October 2012, January 2013, March 2013, or June 2013, when the programs used blended learning. Information from two additional blended cohorts is included only in the student satisfaction data. These cohorts (called Blended 5-6) completed programs in August 2013 or November 2013, when the programs used blended learning.

\section{Design Strategy}

Before blended learning, the phlebotomy technician program used experienced, practicing technical staff to provide subject matter expertise, laboratory supervision, and clinical guidance, although the teaching staff had little experience or formal training in curriculum design and the use of educational technologies. As a starting point, the blended learning project focused on modules referred to as didactic, where the established strategy was to communicate essential knowledge and then assess that knowledge. These modules were replaced by a targeted and planned combination of resources (e.g., the virtual laboratory or computer-mediated learning) and face-toface discussions with an emphasis on confirming knowledge and preparing for laboratory or clinical experiences. The old program, which separated didactic content, laboratory practice, and clinical experience, was transformed into an integrated design. In many ways, this transformation is part of the current trend to use the "flipped classroom", 3 where students are introduced to hands-on skills and knowledge with the expectation that they would come to class with an initial understanding of topics that would be further explored and verified in intensive face-to-face sessions.

\section{Instruments}

Program accessibility was measured by comparing course schedules before and after implementation of blended learning to determine whether the amount of face-to-face time and events decreased. Program efficiency was measured by comparing the number of attempts students required in the laboratory sessions to demonstrate proficiency in three tasks: tourniquet application, hand hygiene, and tube labeling. Learning outcomes were measured with scores on medical terminology, final program, and certification examinations. Student satisfaction was measured with an online post course survey.

Analysis of variance was conducted on the skills proficiency and examination score data. Mann-Whitney analysis was used to compare student satisfaction scores between Blended 1-4 and Blended 5-6 cohorts.

\section{RESULTS}

\section{Participants}

The participants for this study were in six cohorts (two Preblended cohorts and four Blended cohorts) who completed the phlebotomy technician program between May 2012 and June 2013. The majority of students were 18 to 24 years old (Table 1), which would suggest that 
they were familiar with digital technology. However, according to reports from the program director, not all the students were digitally literate. This reinforces the need to ensure that the course design communicates the strategies required to use online learning components and to work independently.

Table 1. Demographics of students in Preblended (May and August 2012) and Blended 1-4 student cohorts (October 2012, January 2013, March 2013, June 2013).

\begin{tabular}{lcc}
\hline & $\begin{array}{c}\text { Pre-blended cohort } \\
(\mathbf{n}=23)\end{array}$ & $\begin{array}{c}\text { Blended 1-4 cohort } \\
(\mathbf{n}=32)\end{array}$ \\
\hline Female & $17(74 \%)$ & $24(75 \%)$ \\
Male & $6(26 \%)$ & $8(25 \%)$ \\
Age 18-24 & $13(57 \%)$ & $21(66 \%)$ \\
Age 25-29 & $2(9 \%)$ & $2(6 \%)$ \\
Age 30-34 & $5(22 \%)$ & $4(13 \%)$ \\
Age 35-39 & 0 & $2(6 \%)$ \\
Age 40-44 & $1(4 \%)$ & $2(6 \%)$ \\
Age 45-49 & $1(4 \%)$ & $1(3 \%)$ \\
Age 50+ & $1(4 \%)$ & 0 \\
\hline
\end{tabular}

\section{Program Accessibility}

A key attribute related to accessibility is the amount of time students are required to be on campus in face-toface interactions with faculty. Before blended learning was implemented, students were required to be on campus five days a week for ten weeks, participating in classroom, laboratory, or clinical rotations for 400 hours, of which 150 were didactic. In the blended learning model, didactic time was reduced by 111.5 hours or $74.3 \%$. The clinical rotation time did not change. Although students are still required to be on campus 47 days, only 35 are eight-hour days. This reduction allows students more flexibility to meet work, child care, and other family and personal obligations. A course syllabus with the schedule of modules/lessons and daily learning activities for the ten week blended course is included as Appendix 1.

Less face-to-face classroom time also makes the program more accessible to learners from a broader geographic area. Learners can commute more easily with fewer classroom hours. With the implementation of virtual classroom technology, the program has the potential to be a partner with other facilities throughout the region and country to offer the program with clinical rotations held at the local site.

Portions of the curriculum were repackaged to provide basic phlebotomy skills to other learners, including physician assistants, medical students, and medical laboratory sciences students. This abbreviated phlebotomy course helped the faculty prepare these student groups for focused learning with fewer classroom and faculty resources than had been necessary in the past, and allowed the school to meet a growing demand without adding faculty.

Phlebotomy employees at Mayo Clinic also benefited from the online modules. Shortly after blended learning was implemented, the Department of Laboratory Medicine and Pathology changed the order in which blood tubes are filled. The interactive exercise that focused on the sequence for drawing blood was updated to reflect the new protocol and was made available to over 300 employees, increasing the efficiency of their education.

\section{Program Efficiency}

As part of the program, students must demonstrate competence in three specific tasks: tourniquet application, hand hygiene, and tube labeling. The number of attempts required by each student to demonstrate proficiency decreased measurably $(40 \%$ for tourniquet application, $20 \%$ for hand hygiene, $28 \%$ for tube labeling) after blended learning program was introduced (Figure 1).

\section{Learning Outcomes}

One measure of success for students is their knowledge of phlebotomy terminology. Mean scores on the terminology examination were not significantly different for the Preblended and Blended 1-4 cohorts (Figure 2), even though most of the preparation for the terminology module shifted from the classroom to online. Similarly, the comprehensive final examination and National Healthcareer Association examination scores were not significantly different between the Preblended and Blended 1-4 cohorts (Figure 2).

\section{Student Satisfaction}

The attitudinal student satisfaction scores were based on participant responses to items 1 through 10 and 14 through 20 on the student satisfaction survey (items 1113 were not attitudinal). Students rated each statement from strongly agree (5 points) to strongly disagree (1 point). Responses from Blended 5-6 cohorts (who completed the program in August or November 2013) were included for the student satisfaction data. The mean 
satisfaction score is presented for each student cohort (Table 2). Because student satisfaction data were obtained from only a small number of students (10 or 11 ) in the Preblended cohort, statistical analysis was not performed to compare student satisfactions scores between Preblended and Blended cohorts.

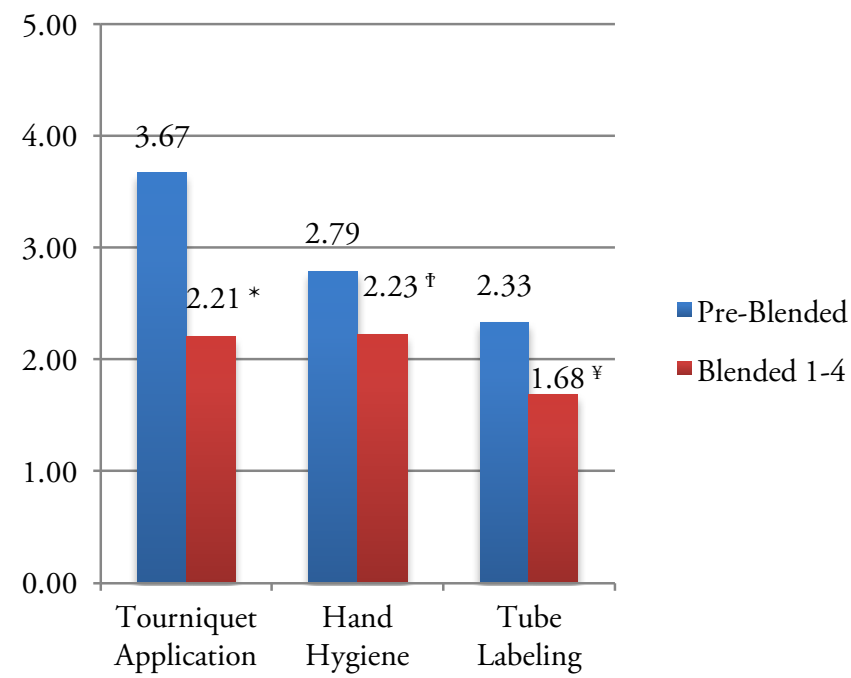

${ }^{*} \mathrm{P}<0.0001$, significant difference in mean attempts at tourniquet application compared to Pre-Blended cohort

$\dagger \mathrm{P}=0.0006$, significant difference in mean attempts at hand hygiene compared to Pre-Blended cohort

$¥ \mathrm{P}=0.0005$, significant difference in mean attempts at tube labelling compared to Pre-Blended cohort

Figure 1. Mean number of attempts to master tourniquet application, hand hygiene and tube labelling in PreBlended cohort (May and August 2012) and Blended 1-4 cohort (October 2012, January 2013, March 2013, June 2013).

Despite the relatively small number of responses from students in the Preblended cohort, faculty members were concerned about the decreased student satisfaction in Blended cohorts 1-4, so the faculty substantially changed the course design. Those changes successfully improved student satisfaction, as shown by significantly higher satisfaction scores for Blended 5-6 cohorts (compared to Blended 1-4) on 13 of the 17 attitudinal questions (Table 2 ). The survey questions that did not show significant changes between Blended 1-4 and Blended 5-6 cohorts were those not directly related to curriculum delivery, such as item 08 (I was challenged to think critically about the subject matter of this course), item 09 (I consider the knowledge and skills I gained valuable for my career), and items related to the laboratory experience (item 16) and facilities and space (item 17) (Table 2). Results for the following three items were selected for particular analysis and discussion because they showed the greatest decrease in student satisfaction initially.

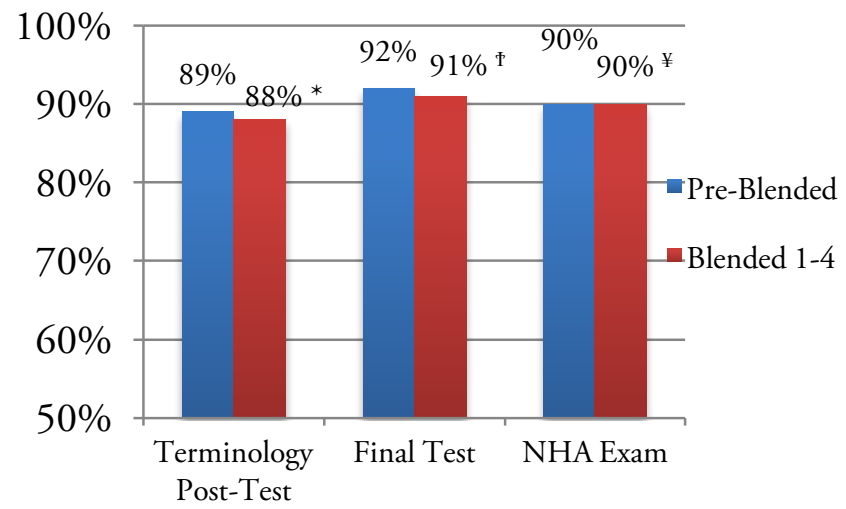

* $\mathrm{P}=0.7092$, no significant difference in mean terminology scores between cohorts

$\dagger \mathrm{P}=0.6205$, no significant difference in mean final test scores between cohorts

$¥ \mathrm{P}=0.5374$, no significant difference in mean NHA exam scores between cohorts

Figure 2. Mean scores on terminology exam, comprehensive final exam, and National Health Career Association ${ }^{\circledR}$ (NHA) certification exam for Pre-Blended cohort (May and August 2012) and Blended 1-4 cohort (October 2012, January 2013, March 2013, June 2013).

Q01: The course was well-organized and sequenced appropriately.

Students in the initial cohorts after blending (Blended 14) were less satisfied with the organization of the course than were students in the Preblended cohorts (Table 2). The quantitative results were supported by comments expressing confusion about the syllabus, assignment due dates, and the location of course materials. Blended 1-4 students also responded less favorably to item 02 (The learning objectives were clearly defined and relevant). The faculty revised the syllabus and formatting of the online modules to clarify what should be done independently and what would be covered in class. They emphasized deadlines, especially for work that they expected students to complete and submit online. The subsequent two cohorts (Blended 5-6) were much more satisfied with the organization of the course (Table 2), and they seemed to better understand expectations related to deadlines and outcomes.

The initial decrease in student satisfaction was not surprising and emphasizes the need for faculty to monitor 


\begin{tabular}{|c|c|c|c|c|c|}
\hline \multicolumn{2}{|r|}{ Item } & \multicolumn{4}{|c|}{ Mean Score } \\
\hline No. & Topic & $\begin{array}{l}\text { Pre-blended } \\
(\mathrm{n}=10 \text { or } 11)\end{array}$ & $\begin{array}{l}\text { Blended } 1-4 \\
(\mathrm{n}=30 \text { or } 31)\end{array}$ & $\begin{array}{c}\text { Blended 5-6 } \\
(n=17)\end{array}$ & P Value \\
\hline 01 & Course well organized & 4.80 & 3.73 & 4.41 & .01 \\
\hline 02 & Learning objectives defined and relevant & 4.80 & 4.13 & 4.65 & .02 \\
\hline 03 & Learning activities supported objectives & 4.70 & 4.29 & 4.71 & .03 \\
\hline 04 & Developed problem-solving skills & 4.90 & 4.10 & 4.53 & .04 \\
\hline 05 & Difficulty level appropriate & 4.60 & 4.16 & 4.65 & .006 \\
\hline 06 & Pace appropriate & 4.50 & 4.00 & 4.76 & $<.001$ \\
\hline 07 & Achieved intended learning objectives & 4.73 & 4.19 & 4.76 & .002 \\
\hline 08 & Challenged to think critically & 4.91 & 4.29 & 4.59 & .11 \\
\hline 09 & Knowledge and skills valuable & 4.91 & 4.53 & 4.76 & .19 \\
\hline 10 & Confident in ability to apply information & 4.82 & 4.39 & 4.76 & .03 \\
\hline 14 & Learning materials relevant and useful & 4.45 & 3.97 & 4.59 & .006 \\
\hline 15 & Technology used enhanced learning & 4.64 & 4.07 & 4.76 & $<.001$ \\
\hline 16 & Laboratory experience helped me apply to real-life situations & 4.82 & 4.42 & 4.53 & .51 \\
\hline 17 & Facilities, space, and equipment suitable & 4.73 & 4.42 & 4.59 & .34 \\
\hline 18 & Adequate opportunities to engage instructor & 4.73 & 4.39 & 4.76 & .04 \\
\hline 19 & Adequate opportunities to engage other learners & 4.73 & 4.23 & 4.71 & .0499 \\
\hline 20 & Overall satisfied with course & 4.82 & 4.43 & 4.82 & .04 \\
\hline
\end{tabular}

student feedback and quickly respond. The blended learning format is new to many students who may initially rely on classroom announcements for navigation through a course. Having the course clearly organized and the learning objectives explicitly stated should help students independently find their way through a course and know the desired outcome or competency.

\section{Q06: The pace of this course was appropriate.}

One question that received considerable comment related to the pace of the course. Students in the Blended 1-4 cohorts felt rushed in some sections and thought that "too much was crammed" into certain parts of the program. Again, the faculty responded to comments. They determined that the large amount of background information about the profession and the legal and ethical considerations of phlebotomy created a heavy workload in the first weeks. They decided that this material could be distributed more evenly throughout the program. The mean score for the subsequent cohorts (Blended 5-6) was not only improved, but in fact higher than the Pre-Blended cohort mean (Table 2). This perceived improvement in the pace of the course could suggest that after the overall pace of the course was adjusted, the more individualized pacing was more satisfactory than the traditional singular track of delivery in the face-to-face classroom.
Q19: I had adequate opportunities to engage in interactions with the other learners in this course.

The mean score for this item decreased from 4.73 in PreBlended to 4.23 in Blended 1-4 cohorts (Table 2). As noted above, the blended learning design of the course decreased the face-to-face classroom time by 111.5 hours. Some of this time was spent in traditional lectures and in more informal debriefings of clinical experiences. After receiving the survey results, the faculty changed the design to accommodate more opportunities for interaction both face-to-face and virtually. First, they added several optional drop-in sessions for students. These sessions allowed students who felt a need for more interaction or assistance to have additional access to the faculty. By not requiring attendance at these sessions, the faculty allowed students who did not need additional assistance to continue to work independently. In addition, the program initiated a private Facebook page for further class interaction. This was intended to supplement face-to-face debriefings after clinical experiences, so that students, while still maintaining patient confidentially, could share their reactions to working with ill or dying patients. Being able to process their responses is an important aspect of the clinical training and their integration into the profession. Mean satisfaction scores on item 19 increased for the Blended 5-6 cohorts (Table 2 ). 


\section{EDUCATION}

In summary, as measured by the mean student responses to the attitudinal survey items, student satisfaction initially decreased after implementing the blended curriculum (Table 2). After the faculty revised the design, student responses improved in subsequent cohorts. When responses to individual questions are considered, despite the initial decrease in the student satisfaction in Blended $1-4$ cohorts, $94 \%$ to $100 \%$ of the students in the Blended 5-6 cohorts responded either "agree" (4) or "strongly agree" (5) to all the attitudinal survey items (data not shown).

\section{Faculty Satisfaction}

Because only three faculty members are involved in classroom and laboratory teaching for the program, a survey tool was not used to solicit their feedback. Although the program director and classroom/laboratory faculty were supportive of implementing blended learning, they were also apprehensive. Faculty were unsure about their ability to assess student understanding of content in the blended format, and were concerned that students might not ask questions in a timely manner when they were not clear on concepts. They were also concerned about reliability of the online technology. Finally they wondered whether all students would take the initiative to learn on their own and be able to stay on schedule working independently. Some faculty efforts to alleviate these concerns included distribution of faculty email and phone numbers to students; and instruction for how to access the web calendar so students were aware when open classroom time was available. Faculty were relieved to find that the information technology help desk was able to solve technical problems quickly, with little down time for the students.

Faculty found that students came to class and laboratory sessions as well prepared, if not better, than they had before blended learning was implemented. Overall, despite the initial time commitment to create the new design, resources, learning activities, and assessments, they are very satisfied with the results and the resulting teaching environment. In addition to the classroom and laboratory faculty, the clinical preceptors reported that they found students better prepared on certain skills such as the order of draw, allowing them to work with students on more complex aspects of their role.

\section{DISCUSSION}

Research into phlebotomy-specific blended or online learning experiences is consistent with that for other areas of the health sciences. One study assessed the performance of undergraduate students to carry out a vein puncture with the support of three digital educational materials: hypertext, educational games, and simulations. Their results indicated that materials aided their learning process, demonstrating the value of digital resources for learning. ${ }^{4} \mathrm{~A}$ second study investigated the effectiveness of a virtual reality phlebotomy simulator compared to a traditional method of teaching blood collection. The author reported that both methods demonstrated a significant improvement over baseline assessments, with the mannequin arm (traditional method) showing a slightly greater improvement. ${ }^{5}$ However, the self-directed learning and metrics recorded by virtual reality (VR) simulation may complement training with the mannequin arm in acquiring basic skills. This not only highlights the value of the digital resources but also the importance of blending those resources appropriately with classroom resources - in this case, the mannequin arm.

The results from this pilot study at Mayo Clinic show that conversion to a blended curriculum in the phlebotomy program was achieved without adversely impacting student performance, while maintaining high student satisfaction, improving course efficiency, and increasing accessibility to students. Our results also emphasize the importance of obtaining and responding to early learner feedback in order to enhance the quality of the course.

Our study was limited in that outcomes of only one ten week phlebotomy technician program were studied, and few preblended student satisfaction surveys were available. Future studies will assess the outcomes of blended learning conversion for the histology technician (nine month program) and clinical neurophysiology program (two year program), to determine whether outcomes observed for the phlebotomy program blended learning transition can be generalized to other allied health training programs.

\section{REFERENCES}

1. Pape, L. Blended Teaching and Learning. Education Digest: Essential Readings Condensed for Quick Review 2010;76(2):22-7.

2. Brandt BF, Quake-Rapp C, Shanedling J, Spannaus-Martin D, Martin, P. Blended learning: Emerging best practices in allied health workforce development. J Allied Health 2010;39(4) 
:e167-72.

3. Bergmann J, Sams, A. Flip your classroom: Reach every student in every class every day. Arlington VA: International Society for Technology in Education (ISTE). 2012.

4. da Silva AP, Cogo, AL. Learning vein puncture using digital educational material in a Nursing Undergraduate Course. Rev Gaucha Enferm 2007;28(2):187-92. Portuguese.

5. Wandell, H.E. Using a virtual reality simulator in phlebotomy training. Lab Med 2010:41(8):463-6.

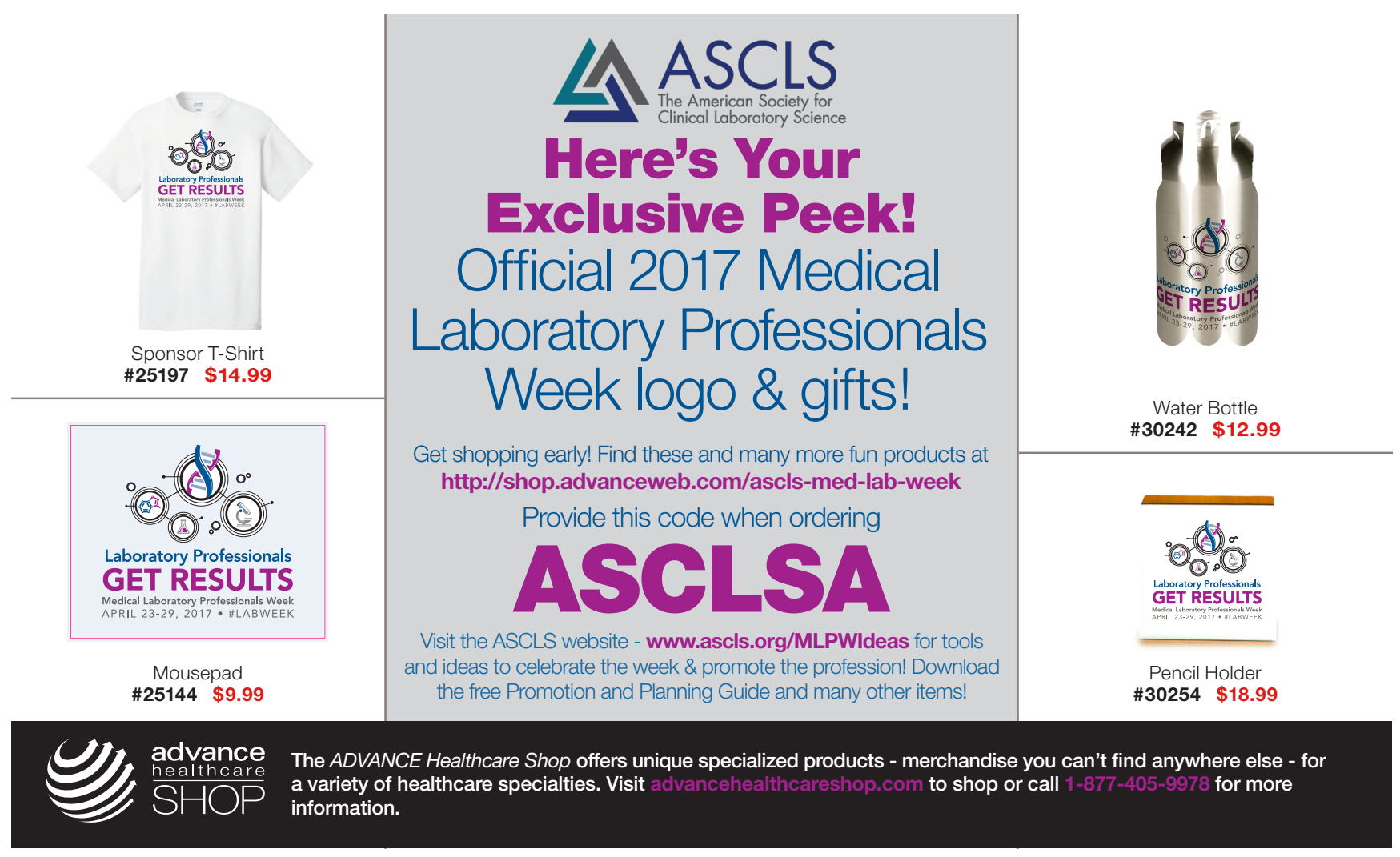

